\title{
The influence of mindfulness and moral disengagement on the psychological health and willingness to work of civil servants experiencing compassion fatigue
}

\author{
Chuang-Hsien $\mathrm{Wu}^{1}$ (D) \\ Published online: 30 April 2020 \\ (C) Springer Science+Business Media, LLC, part of Springer Nature 2020
}

\begin{abstract}
Both public administration scholars and practitioners believe that "good governance" relies on the involvement of compassionate officials. However, they overlook the fact that "compassion fatigue" often occurs when officials face the dual pressure arising from superiors' orders and empathy for service receivers. This would inevitably not only affect their individual behaviors, but also influence the effectiveness of their service. A full-scale investigation of animal protection administrators in Taiwan was conducted so as to analyze compassion fatigue that civil servants would encounter and further establish a relationship between various variables and the hypotheses of this study by combining the studies of public administration and psychology. It should be noted that compassion fatigue may affect animal protection administrators' mental health in spite of little influence on their willingness to work hard. However, both "mindfulness" and "moral disengagement" are coping strategies which were developed for helping tackle the dilemma of compassion fatigue. Although applying the strategy of mindfulness can generate more positive impacts on individuals and organizations than that of moral disengagement, animal protection administrators tended to adopt the latter. Accordingly, encouraging animal protection administrators to adopt mindfulness instead of moral disengagement as their coping strategy will be a priority of work for the authorities in the future.
\end{abstract}

Keywords Compassion fatigue $\cdot$ Moral disengagement $\cdot$ Mindfulness $\cdot$ Animal protection

\section{Introduction}

For a long time, public administration scholars have contended that civil servants with high levels of compassion are necessary for successful governance and boosted government department performance. However, they have overlooked the fact that these civil servants experience severe physical and psychological damage because of their excessive compassion in servicing people. The most severe instance occurred in May 2016, when Dr. YaCheng Chian, who worked in an animal shelter in Taiwan, died from suicide using the drugs that served to euthanize animals

https://sites.google.com/site/nutnwuchuanghsien/ge-ren-jian-li-yuzhuan-zhang

Wu, C.-H. (2019, October 20). compassion fatigue related data. Retrieved from osf.io/n28ef

Chuang-Hsien Wu

wuchuanghsien@gmail.com

1 Department of Public Administration and Management, National University of Tainan, 33, Sec. 2, Shu-Lin St., Tainan 7000, Taiwan because of the psychological stress induced by the job requirement (BBC 2017).

Studies on public administration have mostly focused on helping public servants complete their tasks efficiently and building anticorruption systems. They have neglected the helpless individuals experiencing compassion fatigue because of how dedicated they are to their jobs in massive organizations. This situation may be caused by a certain factor. As Waldo (1980) questioned, "Why would an instrument designed to be impersonal and calculating be expected to be effective in delivering sympathy or compassion?" Fortunately, studies on psychological counseling have focused on the psychological symptoms from overworking due to high levels of compassion. These symptoms include the feelings of helplessness, anxiety, fear, guilt, anger, numbness, and disengagement. Moreover, the professional term "compassion fatigue" was introduced (Figley and Roop 2006), and effective collective and individual adaptation strategies have been proposed in the psychology field to combat compassion fatigue. Research has suggested that if managers collectively can reduce employees' work burden (Keidel 2002; Yoder 2010) and increase organizational (McArthur 
et al. 2017: 9) and social support (Dickinson et al. 2010: 153), employees' psychological health and organizational behavior can remain unaffected by compassion fatigue. Individually, if employees can strengthen their own psychological health (Lally 2005), increase their compassion satisfaction (Figley and Roop 2006), and apply mindfulness (Josefsson et al. 2011) and emotional separation (Corcoran 1983), they can alleviate psychological health deterioration and reduce negative organizational behavior.

However, research has not paid adequate attention to two aspects of compassion fatigue.

First, research on individual-level strategies has not separately considered two effective adaptation strategiesmindfulness (Kabat-Zinn 2016) and emotional separation (Corcoran 1983) - for overcoming compassion fatigue. These have essentially been considered strategies for alleviating negative effects (deteriorating psychological health and organizational behavior). However, we proposed that the effects of mindfulness and emotional separation can vastly differ in administrative organizations. When administrative ethics is applied against the emotional separation strategy, emotional separation becomes highly similar to the "moral disengagement" worried about in administrative ethics. Empirical research has verified that moral disengagement can undermine the personal mental health of civil servants and cause negative organizational behavior. The two mental strategies of mindfulness and moral disengagement appear to have different internal logics; however, studies have not examined and compared these psychological strategies.

Comparisons of mindfulness and moral disengagement in psychological research has mainly discussed effective methods of resolving psychological and organizational problems among civil servants with compassion fatigue from a spectator's perspective.

Few empirical studies have attempted to analyze how concerned parties select coping strategies from their own perspectives. Some of these studies have discovered that individuals experiencing compassion fatigue prefer to cope with moral disengagement to alleviate their moral stress (Kahler 2015) and moral guilt (Nolte et al. 2017). By contrast, other studies have found that individuals experiencing compassion fatigue are unwilling to cope with mindfulness because reexperiencing negative emotions is undesirable.

Few studies have clarified selection strategies for the parties concerned. In addition, how individuals choose between mindfulness or moral disengagement when experiencing compassion fatigue remains to be determined.

The goal of this study was to analyze the levels of compassion fatigue in animal protection administrative units in Taiwan and clarify whether demographic information (e.g., seniority and sex) influences the levels of compassion fatigue. Additionally, the effect of severe compassion fatigue on these units' psychological health and willingness to work was examined. Moreover, the effects of mindfulness and moral disengagement on the negative outcomes from compassion fatigue in these units were clarified. Finally, the strategies these units experiencing compassion fatigue tend to adopt were investigated.

\section{Literature Review}

\section{Flaws in the Studies on Compassion Fatigue and Supplements Offered by Psychology}

Few studies on public administration have focused on the effect of compassion on civil servants' organizational behaviors. With the prevalence of the New Right, most scholars have considered civil servants' behaviors as motivated by rational self-interests. Currently, compassion is not considered the core of public services, and it has not yet been regarded as the cause of negative organizational behaviors. Therefore, the aforementioned case of Dr. Chian's suicide was severely neglected. Psychological studies on compassion fatigue are mandatory to alleviate the compassion fatigue experienced by civil servants.

Joinson (1992) coined the term "compassion fatigue" to refer to the persistent negative emotions, such as anger and feeling of helplessness, experienced by nursing personnel caring for patients. This concept was subsequently expanded to other counseling professions (Harris 2002), such as pastors, counselors, and social workers (Hooper et al. 2010).

Coetzee and Klopper (2010) argued that compassion fatigue is a unique type of fatigue caused by the stress accumulated by some service providers because of their strong psychological association with their patients. The term "fatigue" was replaced by "compassion fatigue" to better describe the negative emotions experienced by nursing personnel directly linked to their compassion (Neville and Cole 2013).

Studies have alluded to the following individual factors of compassion fatigue:

\section{Sex}

As commonly acknowledged by most societies, female employees are willing to partake in jobs designed to help others because they are more compassionate towards disadvantaged people than male employees are. Consequently, female service providers experience higher levels of compassion fatigue than do male service providers (McArthur et al. 2017; Yeung et al. 2017).

\section{Age}

Studies have reported that young people tend to experience greater fatigue (Doolittle 2010; Francis et al., 2009) and 
compassion fatigue (including job fatigue and secondary trauma) than older people do (Burtson and Stichler 2010; Yeung et al. 2017).

\section{Seniority}

When examining data from veterinary students, McArthur et al. (2017) indicated that students with working experience in veterinary hospitals tend to experience lower compassion fatigue than other students. Accordingly, some scholars have contended that seniority predicts fatigue more satisfactorily than age (Randall 2004). Indeed, young workers have not fully developed the necessary skills to mitigate stress (Doolittle 2010).

\section{Job Type}

Nursing studies have indicated that nursing personnel working in hospices (Abendroth and Flannery 2006) and cancer wards (Potter et al. 2010) experience more compassion fatigue than general nursing personnel. Accordingly, nursing personnel working for a long time on mitigating difficulties that cannot be effectively solved are particularly likely to experience severe compassion fatigue.

Compassion fatigue negatively affects service providers in numerous facets, including their psychological health and willingness to work. The physical and psychological symptoms caused by compassion fatigue are similar to those of posttraumatic stress disorder (Jacobsona et al. 2013). People experiencing it tend to feel physical discomfort upon repeatedly, involuntarily remembering major traumatic events even though they try to avoid remembering them (Figley and Roop 2006; Figley 2002a). This causes severe physical problems, including anxiety and depression (Cocker and Joss 2016). Moreover, as a form of damage to the willingness to work, compassion fatigue causes care providers to dissociate with their own emotions to protect themselves. Consequently, care providers become indifferent and disengaged from compassion and tolerance to patients' pain (Figley 2002a; Figley $2002 b$ ), and they become less willing to work.

\section{Mindfulness}

Workers adopt various external strategies to alleviate compassion fatigue, including religion, music, arts (Lally 2005), group counseling, in-service courses and seminars (Berger and Gelkopf 2011), seeking support from managers (Thoits 1995), and distancing from the sources of stress (Yoder 2010). However, because compassion fatigue is a psychological state, the effectiveness of said external strategies entirely depends on whether they successfully transform into internal coping strategies for the people adopting them. Psychological studies have reported that these coping strategies can be divided into active "mindfulness" and passive "emotional separation."

\section{Context of Mindfulness}

Kabat-Zinn (1994) developed a mindfulness-based stress reduction technique, which employs mindfulness as a special approach to observe. Attention is given in a particular manner-on purpose, in the present moment, and nonjudgmentally. Accordingly, mindfulness involves truthfully observing one's own physical and psychological phenomena (Josefsson et al. 2011), patiently observing the immediate physical and psychological states, and observing one's own emotions, thoughts, and pain without judgment (Earley et al. 2014; Brotto et al. 2012).

Several methods to practice mindfulness have been developed, such as sitting and walking meditation, body scan, mindful yoga, and mindfulness in daily life (Kabat-Zinn 1994).

\section{Positive Effect of Mindfulness}

Typically, organizations have attempted to solve problems by increasing the physical resources and providing employees with professional training, such as advanced medical technology and comprehensive policy analysis, to solve problems efficiently and practically. However, all governments and organizations face moments of helplessness, such as in times of war and natural disasters. Even when employees' professional capabilities are comprehensively developed, situations in which patients have incurable diseases (e.g., those in hospice wards) or are in desperate conditions (e.g., veterinarians euthanizing sheltered animals because of shortage in resources) are bound to occur and impede the usefulness of their professional skills.

Studies have reported numerous positive effects of mindfulness on employees' psychological health. Bolduc et al. (2018) maintained that mindfulness training enables adults to alleviate traumatic experiences they have sustained from their childhood. In an organization, when employees are mindful of their own psychological symptoms, they can preemptively prevent the negative effects these symptoms bring about (Bride et al. 2007). Subsequently, they can face their own psychological trauma compassionately and nonjudgmentally (Neff 2003a; Neff 2003b).

Mindfulness also positively affects organizational behaviors. Care providers that are capable of mindfulness can avoid escapist behaviors and understand in depth the spiritual state of care receivers. They are able to find hope and strength in care receivers' traumatic experience and accompany them in their spiritual journey until the end of their life with respect. Moreover, they understand the situations in which people feel helpless (e.g., accidents, failure of strength, and death) and 
apply it in their activities and interpersonal interactions, gaining physical and psychological healing (Hsu et al. 2016). Care providers are more active at work when they see the positive value of their job. According to Hyland et al. (2015) and Chaskalson (2011), mindfulness positively affects people's willingness to work.

\section{Why People Experiencing Compassion Fatigue Resist the Mindfulness Strategy?}

Although mindfulness can be practiced to mitigate the damage compassion fatigue causes to employees' psychological health and willingness to work, people who have sustained psychological trauma tend to refuse to practice a mindfulness strategy. According to Rosenthal et al. (2005), people who have experienced sexual assault in their childhood tend to avoid receiving mindfulness guidance to protect themselves from having to face internal emotional experience. Consequently, they are particularly likely to remain trapped in negative emotions and increased stress (Daigneault et al. 2016). Accordingly, employees sustaining compassion fatigue tend to subconsciously resist mindfulness to preserve themselves from undergoing an internal emotional experience.

\section{Emotional Separation and Moral Disengagement}

In addition to mindfulness, care providers faced with compassion fatigue may adopt strategies with which they distance themselves physically and psychologically from the sources of stress (e.g., care receivers and their difficulties), for example by taking vacations, reducing their amount of work, or temporarily leaving workplaces. This way, care providers regain the energy and space necessary to recover their physical and psychological health (Keidel 2002; Yoder 2010). However, this strategy can lead to moral disengagement when applied by civil servants, who possess administrative discretion. To distance themselves from moral stress, civil servants may morally justify their irresponsibility as being a coping strategy. Therefore, mindfulness is defined as an adaptive coping strategy, whereas moral disengagement is regarded as a maladaptive coping strategy (Zander et al. 2010).

\section{Context of Moral Disengagement}

In moral disengagement, people morally justify the unethical behaviors they have adopted to reduce their sense of moral guilt (Fiske 2004; Bandura 1986; Bandura et al. 1977; Bandura 1990). Bandura (1990) defined four types of moral disengagement mechanisms as follows: (1) moral justification, which involves justifying one's own behaviors when detrimental consequences have not surfaced; for example, the euthanasia of stray dogs has been justified as a means to save a country's finances; (2) minimization of consequences, which involves disregarding or distorting consequences when they surface; for example, care providers may anesthetize the moral guilt felt from causing the death of a puppy by failing to provide warmth-keeping measures by giving excuses such as they did not know low temperature would kill it; (3) nonresponsibility, which involves blaming negative results on other people's mistakes to mask one's own guilt; for example, stray dog problems may be presented as a responsibility shared by the negligence of the society, families that have abandoned the dogs, and pet shop owners; (4) dehumanization, which involves blaming victims for negative outcomes; for example, stray animals who have been abandoned by their owners can be blamed for their own behavioral problems.

\section{Negative Consequences of Moral Disengagement}

Moral disengagement exacerbates organization members' psychological health and causes them to adopt negative organizational behaviors. Empirical studies have confirmed that organizational members experiencing negative emotions because of job stress adopt counterproductive work behaviors (Caprara et al. 2012), such as withholding efforts (Fida et al. 2015), anger, and hostility (Wang et al. 2017), all of which impede their psychological health.

\section{Why People Experiencing Compassion Fatigue Choose Moral Disengagement?}

Medical and disaster relief personnel experience compassion fatigue when they fail to attain their goal of making organizations sympathize with wounded individuals. Civil servants, who possess administrative discretion, have their compassion fatigue exacerbated when they are forced to restrict and halt the provision of care to disadvantaged people to satisfy the orders from hierarchy, which lead them to experience moral stress (Kahler 2015). These civil servants tend to attempt alleviating their moral stress through moral disengagement. That is, they justify their negative behaviors to relieve themselves from moral guilt (Nolte et al. 2017).

\section{Research Design}

Causal relationships identified from experimental research (or interventional studies) are precise; however, inviting working civil servants to engage in a group experimental design is difficult. Therefore, we adopted descriptive research for the experimental design, and this can be separated into categories such as case reports, case series, and correlational and crosssectional studies (Omair 2015: 154). We aimed to have strong evidence for our study and did not adopt case report and case series as our research methods. Our data was not secondary data from international or interdepartmental sources. 
Therefore, we did not use correlation research, instead using cross-sectional research.

Cross-sectional (or prevalence) studies are easy to conduct and are the most common study designs used in most medical journals. Surveys can be completed quickly depending upon the sample size required and access to the study population. Cross-sectional studies can be classified as analytical study designs if a relationship is determined between exposure and outcome. Other special methods were used to establish our cross-sectional study.

\section{Research Hypotheses}

To clarify the overall level of compassion fatigue experienced by animal protection administration personnel and the effects of individual characteristics on their compassion fatigue, a statistical analysis of compassion fatigue was conducted, and the following hypotheses were formed according to a literature review:

H1: Female employees experience higher levels of compassion fatigue than male employees.

H2: People of a younger age experience higher levels of compassion fatigue.

H3: Employees with less seniority experience higher levels of compassion fatigue.

H4: Employees' levels of compassion fatigue differ according to the administrative duties they are allocated in the animal protection system.

Compassion fatigue has also been indicated to negatively affect people's willingness to work and psychological health according to a literature review. Accordingly, Hypotheses 5 and 6 were formed as follows:

H1: Compassion fatigue negatively affects the willingness of animal protection administrative personnel to work.

$\mathrm{H} 2$ : Compassion fatigue negatively affects the psychological health of animal protection administrative personnel.

Studies have indicated that accumulated compassion fatigue negatively affects individuals and organizations in several aspects, prompting individuals to cope with it through various strategies. When compassion fatigue accumulates, individuals tend to opt for moral disengagement over mindfulness. Accordingly, Hypotheses 7 and 8 were formed as follows:

H1: People with higher levels of compassion fatigue are more likely to adopt the strategy of moral disengagement.
H2: People with higher levels of compassion fatigue are less likely to adopt the strategy of mindfulness.

Studies have contended that mindfulness strengthens people's willingness to work as well as their psychological health. Accordingly, Hypotheses 9 and 10 were formed as follows:

H1: Mindfulness positively affects people's willingness to work.

H2: Mindfulness positively affects people's psychological health.

Studies have confirmed that moral disengagement weakens people's willingness to work as well as their psychological health. Accordingly, Hypotheses 11 and 12 were formed as follows:

H1: Moral disengagement negatively affects people's willingness to work.

H2: Moral disengagement negatively affects people's psychological health.

\section{Variables and Measurement Instruments}

All questionnaire items adopted in this study were translated from their original sources. To ensure their reliability and validity, the scales were revised according to the opinions provided by two public administration experts and two animal protection experts. The research population consisted of 30 employees recruited from the Tainan City Animal Health Inspection and Protection Office for a pretest, after which valid questionnaire items were identified and adopted for the actual survey. With the exception of a few items from the psychological health and mindfulness scales, all other items were retained.

A 5-point Likert scale was adopted for all questionnaires, ranging from 1 (strongly disagree) to 5 (strongly agree) in scores. The variables are described in the rest of this subsection. See Appendix Table 5 for the analysis results of related factors.

\section{Compassion Fatigue Scale}

In the present study, compassion fatigue was defined by symptoms resulting from care providers' long-term, continual traumatic experience induced by their desire to help trauma victims. The compassion fatigue scale in this study was translated from the Compassion Fatigue Short Scale developed by Adams et al. (2006) and slightly revised with animals as the targets of compassion. The scale consisted of 13 items. According to the factor analysis results, the Kaiser-Meyer- 
Olkin (KMO) and Cronbach $\alpha$ values of the scale were .907 and .909 , respectively.

\section{Scale of Willingness to Work}

The seven items of this scale were translated from those devised by Leisink and Steijn (2009). According to the factor analysis results, all the items belonged to the same construct, and the KMO and Cronbach $\alpha$ values of the scale were .870 and .848 , respectively.

\section{Psychological Health Questionnaire}

This scale was based on and translated from the General Health Questionnaire created by Goldberg (1972). After the pretest, a total of five items were retained. According to the factor analysis results, the $\mathrm{KMO}$ and Cronbach $\alpha$ values of the scale were .752 and .754 , respectively.

\section{Moral Disengagement Scale}

The eight items of this scale were based on those devised by Moore et al. (2012) according to eight cognitive mechanisms that disrupt people's internal moral consciousness, and they were slightly revised with animals as the targets of disengagement. According to the factor analysis results, the KMO and Cronbach $\alpha$ values of the scale were .773 and .788, respectively.

\section{Mindfulness Scale}

The items of this scale were based on and translated from the Toronto Mindfulness Scale introduced by Lau et al. (2006) and slightly revised. After the pretest, a total of seven items were retained. According to the factor analysis results, the $\mathrm{KMO}$ and Cronbach $\alpha$ values of the scale were .906 and .927 , respectively.

\section{Control Variables}

The sex, age, seniority, and job characteristics of the participants were defined as control variables to clarify the relationship between independent variables and dependent variables.

\section{Questionnaire Survey and Analysis}

\section{Research Participants}

A total of 340 Taiwanese animal protection administrative workers were surveyed. In addition to general animal rescue, animal protection administrative tasks include slaughterhouse monitoring, animal laboratory inspection, and stray animal shelter management (e.g., adoption, care, and euthanasia). This adds to the compassion fatigue that the participants experience when they witness situations of slaughter, abuse, casualty, and live experiments on animals. Therefore, animal protection administrative personnel were deemed more suitable of this study. The questionnaires were distributed from July 15 to September 15, 2017 and recycled a total of 302 questionnaires.

\section{Questionnaires Distribution and Gathering}

A census questionnaire survey was conducted. The questionnaires were distributed from July 15 to September 15, 2017. The printed questionnaires were enclosed in envelopes and distributed. After the respondents completed the questionnaires, they enclosed the questionnaires in the attached enveloped and sent them back to return address. This was meant to reduce the doubts respondents might have had answering a survey. See Table 1 for the demographic information of the respondents.

\section{Data Analysis}

SPSS 20.0 was employed for the statistical analysis performed on the returned data. The missing data were identified as randomly omitted and were supplemented through mean interpolation. The statistical skewness value of each questionnaire item was $<2$, and its kurtosis value was $<7$ (Appendix Table 5). Therefore, the questionnaire fulfilled multivariate normal distribution and was applicable for regression analysis (Kline 2005).

Each question was analyzed using a unique statistical method. First, means and standard deviations were used in a descriptive statistical analysis on the variables related to the participants' compassion fatigue. Second, a multiple regression analysis was performed on the effects of the demographic information on the participants' compassion fatigue to verify the validity of Hypotheses 1-4. To verify that of Hypotheses 5, 6, 9, 10,11 , and 12 , a multiple regression analysis was conducted on the effects of compassion fatigue, mindfulness, and moral disengagement after the demographic variables were controlled. In addition, a multiple regression analysis was conducted to determine whether people with higher levels of compassion fatigue were more likely to choose moral disengagement over mindfulness. That is, the validity of Hypotheses 7 and 8 was verified. The effect of compassion fatigue on people's choice between mindfulness and moral disengagement was examined.

The demographic information of the civil servants investigated in this study was defined using discrete variables (i.e., nominal or ordinal variables). Before the regression analysis 
Table 1 demographic information of the respondents

\begin{tabular}{|c|c|c|}
\hline Variables & Values & Numbers \\
\hline \multirow[t]{2}{*}{ Sex } & Male & 159 \\
\hline & Female & 136 \\
\hline \multirow[t]{3}{*}{ Age } & $<30$ & 80 \\
\hline & $31-40$ & 112 \\
\hline & $>41$ & 103 \\
\hline \multirow[t]{5}{*}{ Seniority } & $<1$ & 56 \\
\hline & $1 \sim 3$ & 101 \\
\hline & $3 \sim 6$ & 68 \\
\hline & $6 \sim 9$ & 31 \\
\hline & $>9$ & 38 \\
\hline \multirow[t]{12}{*}{ job characteristics } & Rescue aid & 116 \\
\hline & Euthanasia & 47 \\
\hline & Body cremation & 66 \\
\hline & Animal sterilization & 112 \\
\hline & Case investigation & 123 \\
\hline & Wild animal protection & 39 \\
\hline & Pet registration & 118 \\
\hline & Animal control & 89 \\
\hline & Animal adoption & 128 \\
\hline & Animal protection education & 124 \\
\hline & Shelter management & 96 \\
\hline & Shelter cleaning & 39 \\
\hline
\end{tabular}

Source: Data compiled in this study

was conducted, these variables were converted to dummy variables to assign them the characteristics of continuous variables, and they were subsequently applied as predictor variables in multiple regression analysis.

\section{Results}

\section{Differences between Participants in Terms of Compassion Fatigue}

The average compassion fatigue score of the participants was 2.84, and the standard deviation was 0.691. Compared with other variables, the mean score of compassion fatigue was the lowest, but its standard deviation was the highest. In other words, compassion fatigue appeared to be the problem of a handful of employees rather than a prevalent problem among all employees. Therefore, the tragic suicide of Dr. Chian might have only been one of few extreme cases of compassion fatigue. A targeted search together with an appropriate compassion fatigue alleviation method should be adopted to solve the compassion fatigue problem among animal protection administrative personnel.
Table 2 lists the multiple regression analysis results on the effects of the demographic variables on compassion fatigue. Sex and Seniority affected compassion fatigue significantly. The $\beta$ values of sex and age were .125 $(p<.05)$ and $.184(p<.01)$, respectively. The male participants experienced higher compassion fatigue levels than the female participants, and the senior participants experienced higher compassion fatigue levels than junior ones. By contrast, job content and age did not affect compassion fatigue significantly $(p>.05)$.

Accordingly, the effects of the demographic and job characteristics of animal protection administrative personnel on their compassion fatigue identified in this study differed from those reported in previous studies. Because the male participants experienced higher compassion fatigue levels than the female participants, Hypothesis 1 was rejected. Similarly, because the senior participants experienced higher compassion fatigue levels than the junior ones, Hypothesis 3 was rejected. Finally, because neither age nor job characteristics were significantly associated with compassion fatigue, Hypotheses 2 and 4 were also rejected. These results warrant further investigation.

Table 2 Effects of the demographic and job characteristics of the participants on their compassion fatigue

\begin{tabular}{|c|c|c|c|}
\hline \multirow[t]{3}{*}{ Dependent variable } & \multicolumn{3}{|c|}{ Compassion fatigue } \\
\hline & \multicolumn{3}{|l|}{ (M1) } \\
\hline & Beta & $T$ & VIF \\
\hline \multicolumn{4}{|l|}{ Independent variable } \\
\hline Sex & $.125^{*}$ & 2.188 & 1.224 \\
\hline Age & .006 & .096 & 1.366 \\
\hline Seniority & $.184 * *$ & 3.125 & 1.295 \\
\hline Rescue aid & .060 & .872 & 1.762 \\
\hline Euthanasia & .123 & 1.874 & 1.615 \\
\hline Body cremation & .013 & .185 & 1.719 \\
\hline Animal sterilization & -.005 & -.085 & 1.267 \\
\hline Case investigation & .104 & 1.800 & 1.254 \\
\hline Wild animal protection & -.093 & -1.679 & 1.149 \\
\hline Pet registration & -.048 & -.802 & 1.359 \\
\hline Animal control & -.063 & -.986 & 1.543 \\
\hline Animal adoption & -.025 & -.371 & 1.649 \\
\hline Animal protection education & .043 & .759 & 1.201 \\
\hline Shelter management & .005 & .072 & 1.564 \\
\hline Shelter cleaning & -.088 & -1.501 & 1.270 \\
\hline Adjusted $\mathrm{R}^{2}$ & \multicolumn{3}{|l|}{.049} \\
\hline$F$ & \multicolumn{3}{|l|}{$2.210 * *$} \\
\hline$\Delta F$ & \multicolumn{3}{|l|}{$2.210 * *$} \\
\hline
\end{tabular}

Source: Data compiled in this study

Note: $* p<.05 ; * *<<.01$ 


\section{Effects of Compassion Fatigue, Mindfulness, and Moral Disengagement}

\section{Effects on the Willingness to Work of Civil Servants}

Hypotheses 5, 9, and 11 were formulated to clarify the effects of compassion fatigue, mindfulness, and moral disengagement on the willingness of animal protection administrative personnel to work. After controlling the demographic variables, the numerical values of said effects were examined. According to M2 in Table 3, the standardized regression coefficient $(\beta)$ and regression coefficient test results ( $t$ ) were as follows: (1) effect of compassion fatigue on the willingness to work: $\beta=.059, \mathrm{t}=1.221$; the level of significance was not reached $(p>.05)$; (2) effect of mindfulness on the willingness to work: $\beta=.461, t=9.772$; the level of significance was reached $(p<.001)$; (3) effect of moral disengagement on the willingness to work: $\beta=-.132, \mathrm{t}=$ -2.806 ; the level of significance was reached $(p<.01)$. Accordingly, Hypothesis 5 was rejected, whereas Hypotheses 9 and 11 were supported. Notably, although previous studies have indicated that compassion fatigue undermines the willingness to work, this study revealed that animal protection administrative personnel continued to be dedicated to their jobs despite their experience of compassion fatigue.

\section{Effects on the Psychological Health of Civil Servants}

Hypotheses 6, 10, and 12 were proposed to clarify the effects of compassion fatigue, mindfulness, and moral disengagement on the psychological health of animal protection administrative personnel. After controlling the demographic variables, the numerical values of said effects were examined. According to M3 in Table 3, the standardized regression coefficient $(\beta)$ and regression coefficient test $(t)$ results were as follows: (1) effect of compassion fatigue on psychological health: $\beta=-.490, \mathrm{t}=-11.522$ $(p<.001)$; (2) effect of mindfulness on psychological health: $\beta=.316, t=7.569(p<.001)$; (3) effect of moral disengagement on psychological health: $\beta=-.163, \mathrm{t}=-3.913(p<.001)$. All effects satisfied the level of significance. Accordingly, Hypotheses 6, 10, and 12 were supported.
Table 3 Effects of compassion fatigue, mindfulness, and moral disengagement on participants' willingness to work and psychological health

\begin{tabular}{|c|c|c|c|c|c|c|}
\hline \multirow[t]{3}{*}{ Dependent variable } & \multicolumn{3}{|c|}{ Willingness to work } & \multicolumn{3}{|c|}{ Psychological health } \\
\hline & \multicolumn{3}{|l|}{ (M2) } & \multicolumn{3}{|l|}{ (M3) } \\
\hline & Beta & $t$ & VIF & Beta & $t$ & VIF \\
\hline \multicolumn{7}{|l|}{ Control variable } \\
\hline Sex & .006 & .116 & 1.264 & .016 & .365 & 1.264 \\
\hline Age & .080 & 1.523 & 1.351 & .054 & 1.173 & 1.351 \\
\hline Seniority & .034 & .665 & 1.302 & $.104 *$ & 2.269 & 1.302 \\
\hline Rescue Aid & .040 & .670 & 1.789 & .072 & 1.344 & 1.789 \\
\hline Euthanasia & .013 & .231 & 1.589 & -.045 & -.895 & 1.589 \\
\hline Body cremation & .033 & .561 & 1.647 & .022 & .430 & 1.647 \\
\hline Sterilization & .080 & 1.579 & 1.272 & -.007 & -.162 & 1.272 \\
\hline Case inspection & .042 & .821 & 1.256 & -.037 & -.827 & 1.256 \\
\hline Wild animal protection & $.096 *$ & 1.989 & 1.149 & .077 & 1.787 & 1.149 \\
\hline Pet registration & -.013 & -.248 & 1.261 & .015 & .335 & 1.261 \\
\hline Animal control & -.016 & -.281 & 1.552 & -.035 & -.697 & 1.552 \\
\hline Animal protection education & .081 & 1.646 & 1.199 & .065 & 1.476 & 1.199 \\
\hline Shelter management & .013 & .242 & 1.369 & -.014 & -.292 & 1.369 \\
\hline \multicolumn{7}{|l|}{ Independent variable } \\
\hline Compassion fatigue & .059 & 1.221 & 1.133 & $-.490 * * *$ & -11.522 & 1.133 \\
\hline Mindfulness & $.461 * * *$ & 9.772 & 1.094 & $.316 * * *$ & 7.569 & 1.094 \\
\hline Moral disengagement & $-.132 * *$ & -2.806 & 1.091 & $-.163 * * *$ & -3.913 & 1.091 \\
\hline $\mathrm{R}^{2}$ & \multicolumn{3}{|l|}{.309} & \multicolumn{3}{|l|}{.458} \\
\hline Adjusted $\mathrm{R}^{2}$ & \multicolumn{3}{|l|}{.277} & \multicolumn{3}{|l|}{.433} \\
\hline$F$ & \multicolumn{3}{|l|}{$9.496 * * *$} & \multicolumn{3}{|l|}{$17.929 * * *$} \\
\hline$\Delta F$ & \multicolumn{3}{|l|}{$36.366^{* * *}$} & \multicolumn{3}{|l|}{$83.348 * * *$} \\
\hline
\end{tabular}

Source: Data compiled in this study

Note: $* p<.05 ; * * p<.01 ; * * * p<.001$ 


\section{Effect of Compassion Fatigue on Employees' Choice of Coping Strategies}

As seen in Table 4, compassion fatigue significantly affected whether employees favored mindfulness $(p<0.05)$ or moral disengagement $(p<0.001)$. The Beta values for the selection of mindfulness and moral disengagement were negative $(-.108)$ and positive (.227), respectively, indicating that employees experiencing compassion fatigue are more prone to opt for moral disengagement than are those not experiencing compassion fatigue. At the same time, employees experiencing compassion fatigue are less willing to opt for mindfulness. Therefore, Hypotheses 7 and 8 were supported.

However, the implications of the adjusted $\mathrm{R}^{2}$ values in Table 4 merit mentioning because they explain the extent to which the predictors influenced the response variable considering that they were very low (.009 and .049). This indicated other predictors not covered in this paper. According to previous empirical research, factors of each of the three dimensions - the individual, organizational, and social — can determine whether an individual adopts mindfulness or moral disengagement as a coping strategy. For example, individuals who adopt mindfulness tend to be older (Mahlo and Windsor 2020) and needs to be exposed to specific organizational conditions, such as high leadership, relative priority, strong networks and effective communications, formally appointed implementation leaders, and knowledge and beliefs about intervention and execution (Hudson et al. 2020); they are also influenced by social cognition (Beattie et al. 2020). By comparison, as for whether an individual adopts moral disengagement as a strategy, personality (e.g., extraversion) was noted to be influential (Mazzone and Camodeca 2019) in addition to the threat of job insecurity (Probst et al. 2020) and social worldview - such as social cynicism or fate control (Alexandra 2019). We have not included these factors in our

Table 4 Effect of compassion fatigue on the choice of mindfulness or moral disengagement strategy

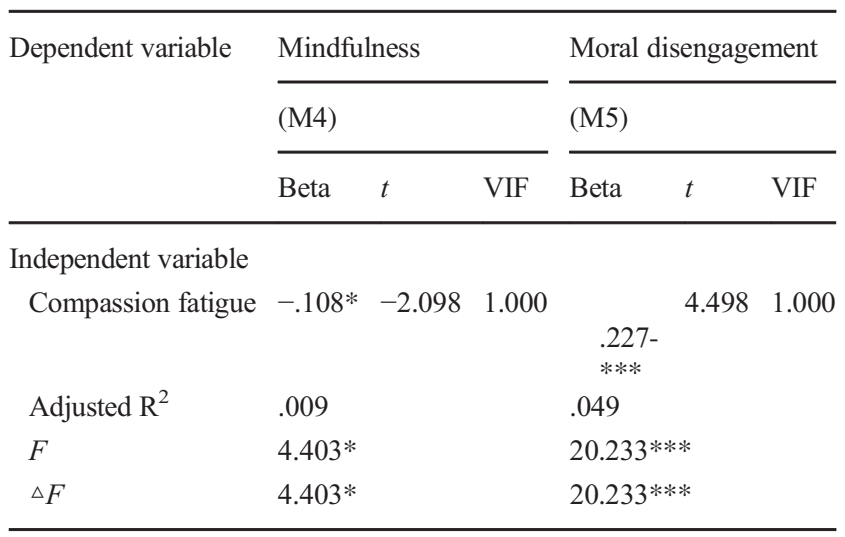

Source: Data compiled in this study

Note: $* p<.05 ; * * p<.01 ; * * * p<.001$ study, but their predictability is potentially higher than that of compassion fatigue factors.

\section{Research Findings and Future Research Directions}

\section{Research Findings and Policy Suggestions}

\section{Take both Willingness to Work and Psychological Health into Consideration}

The results of this study revealed that compassion fatigue does not affect the willingness to work (rejecting Hypothesis 5) but does impede psychological health (supporting Hypothesis 6). This indicates that animal protection administrative personnel experiencing compassion fatigue remain dedicated to their work but continually experience psychological health damage. If these employees are unable to leave their job positions, tragedies similar to that of Dr. Chian might recur. In the current performance-oriented trend of administrative management, most managers focus on employees' willingness to work and job performance while overlooking their psychological needs. Accordingly, managers should not only focus on employees' willingness to work but also take their psychological health into account to preemptively detect their compassion fatigue and offer them timely assistance.

\section{Using Demographic Characteristics as Compassion Fatigue Indicators}

The mean level of compassion fatigue of animal protection administrative personnel in this study was relatively low, but its standard deviation was considerably high. Accordingly, administrative personnel with particularly severe compassion fatigue such as Dr. Chian are relatively rare, but those people's scores on compassion fatigue are extremely high. These employees should be correctly identified through a selection process to improve the effectiveness of counseling resources available and prevent predictable consequences. The results of this study also revealed that male employees and those with more seniority exhibit higher compassion fatigue levels. The government should actively assist these categories of employees and understand their coping strategies and counseling needs.

\section{Correct Employees' Intuitive Tendencies to Adopt Moral Disengagement}

Mindfulness and moral disengagement differ considerably in their effects as psychological coping strategies 
people adopt in response to difficulties at work. The results of empirical studies have indicated that mindfulness improves employees' willingness to work and their psychological health, whereas the opposite is true for moral disengagement. However, the results of the present study revealed that employees experiencing compassion fatigue tend to intuitively adopt moral disengagement rather than mindfulness. Therefore, when faced with potential problems in employees' individual and organizational behaviors, the government should not simply passively suggest them to keep an emotional distance from the targets of their sympathy. On the contrary, the government should actively encourage them to choose mindfulness over moral disengagement as their coping strategy.

\section{Methods to Apply Mindfulness as Coping Strategy}

To encourage employees to adopt the strategy of mindfulness, organizations should proactively provide psychological counseling to employees that are likely to experience or have experienced compassion fatigue, for example through inservice courses, seminars, workshops, and case discussion. Courses can be designed based on existing studies, such as the Circle of Care Retreat (Medland et al. 2004) and NOTECHS model for high-risk professions including aviation (Flin and Maran 2004). These counseling course designs are aimed at improving employees' awareness of their own psychological state, thereby encouraging them to cope with compassion fatigue through mindfulness rather than moral disengagement.

\section{Suggestions for Future Studies}

\section{Investigate Further the Effects of Demographic Variables and Mindfulness}

Studies have contended that female employees were more prone to compassion fatigue than male employees because they were more sensitive and more willing to experience compassion. Younger employees with less seniority were also classified as more vulnerable to compassion fatigue because they have not developed satisfactory emotional coping strategies. These arguments, however, were deconstructed in this study. Further qualitative research is warranted to clarify the reasons why male employees and employees with more seniority are more prone to compassion fatigue and why age and job contents do not affect the compassion fatigue level of animal protection administrative personnel.
Understand the Influence of Awareness of Psychological State

The results of this study revealed that people experiencing compassion fatigue tend to intuitively reject mindfulness and adopt moral disengagement instead. Studies have reported that people can stop themselves from falling into automatic physiological reactions if they are aware of their detrimental physical and psychological state (Bride et al. 2007). Therefore, future studies should employ quantitative surveys to examine the influence of individuals' awareness as a moderating variable to the effect of compassion fatigue on their choice between mindfulness and moral disengagement.

\section{Investigate how Other Predictors Influence Mindfulness and Moral Disengagement}

The values of the adjusted $\mathrm{R}^{2}$ in Table 4 were very low (.009 and .049). This indicated other predictors not covered in this paper. As mentioned, these predictors could be factors from the individual, organizational, or social dimensions. Mindfulness had strong positive effects, and moral disengagement had strong negative effects. Therefore, if employees are led to adopt mindfulness rather than moral disengagement, their psychological health and organizational behavior can be improved. However, studies have mainly regarded mindfulness and disengagement as predicted variables and have attempted to understand the effects generated by these them. Future research can benefit from comprehensively and systematically focusing on compassion fatigue from concerned parties' perspectives and identifying factors influencing civil servants' adoption of mindfulness (or moral disengagement) strategies. This can enable the practical industry to guide civil servants to generate mindfulness and avoid moral disengagement (Table 5).

Research Interests Public Personnel Management, Animal Welfare Policy.

Funding Information Funding resource: Ministry of Science and Technology, Taiwan. Award Number: 105-2410-H-024-001-.

\section{Compliance with Ethical Standards}

All procedures performed in studies involving human participants were in accordance with the ethical standards of National Cheng Kung University Human Research Ethics Committee (Approval No. NCKU HRECE-105-043-2) and with the 1964 Helsinki declaration and its later amendments or comparable ethical standards.

Conflict of Interest The author states that there is no conflict of interest. 


\section{Appendix}

Table 5 Factor and validity analysis results of the questionnaire items

\begin{tabular}{|c|c|c|c|c|c|c|c|c|}
\hline Factor & Number & Item & $\begin{array}{l}\text { Factor } \\
\text { load }\end{array}$ & Skewness & Kurtosis & $\begin{array}{l}\text { Harman's } \\
\text { one factor } \\
\text { test } \\
\text { Explained } \\
\text { variation }\end{array}$ & $\mathrm{KMO}$ & $\alpha$ \\
\hline \multirow{13}{*}{$\begin{array}{l}\text { Compassion } \\
\text { Fatigue }\end{array}$} & 1 & I have felt trapped by my work. & .729 & -.066 & -.377 & 21.379 & \multirow[t]{13}{*}{.907} & \multirow[t]{13}{*}{.909} \\
\hline & 2 & $\begin{array}{l}\text { I have thoughts that I am not succeeding } \\
\text { in achieving my life goals. }\end{array}$ & .726 & .176 & -.378 & 14.477 & & \\
\hline & 3 & I feel that I am a "failure" in my work. & .649 & .410 & -.073 & 6.971 & & \\
\hline & 4 & $\begin{array}{l}\text { I have felt a sense of hopelessness associated } \\
\text { with working with animals. }\end{array}$ & .635 & .073 & -.613 & 5.857 & & \\
\hline & 5 & $\begin{array}{l}\text { I have frequently felt weak, tired or rundown } \\
\text { as a result of my work as a animals carer. }\end{array}$ & .825 & -.132 & -.692 & 4.917 & & \\
\hline & 6 & I have felt depressed as a result of my work. & .846 & .045 & -.666 & 3.376 & & \\
\hline & 7 & $\begin{array}{l}\text { I feel I am unsuccessful at separating work } \\
\text { from my personal life. }\end{array}$ & .730 & .473 & -.469 & 2.909 & & \\
\hline & 8 & $\begin{array}{l}\text { I have a sense of worthlessness, } \\
\text { disillusionment, or resentment } \\
\text { associated with my work. }\end{array}$ & .791 & .205 & -.536 & 2.608 & & \\
\hline & 9 & $\begin{array}{l}\text { I have had flashbacks connected to } \\
\text { my animals. }\end{array}$ & .778 & -.040 & -.303 & 2.507 & & \\
\hline & 10 & $\begin{array}{l}\text { I experience troubling dreams similar to } \\
\text { those of an animal of mine. }\end{array}$ & .843 & .344 & -.177 & 2.369 & & \\
\hline & 11 & $\begin{array}{l}\text { I have experienced intrusive thoughts } \\
\text { after working with an especially } \\
\text { difficult animal. }\end{array}$ & .857 & -.182 & -.539 & 2.145 & & \\
\hline & 12 & $\begin{array}{l}\text { I have suddenly and involuntarily recalled } \\
\text { a frightening experience while working } \\
\text { with an animal. }\end{array}$ & .833 & .282 & -.422 & 2.085 & & \\
\hline & 13 & $\begin{array}{l}\text { I am losing sleep over an animal's traumatic } \\
\text { experiences. }\end{array}$ & .840 & .266 & -.188 & 1.844 & & \\
\hline \multirow[t]{7}{*}{$\begin{array}{l}\text { Willingness } \\
\text { to work }\end{array}$} & 1 & $\begin{array}{l}\text { I help new workers, even when not } \\
\text { required to do so. }\end{array}$ & .724 & -.149 & -.083 & .762 & \multirow[t]{7}{*}{.870} & \multirow[t]{7}{*}{.848} \\
\hline & 2 & I stay late if necessary to help out. & .717 & -.791 & .811 & 689 & & \\
\hline & 3 & I make suggestions for improvements. & .730 & -.177 & -.081 & .664 & & \\
\hline & 4 & I volunteer for things that are not part of the job. & .701 & -.144 & -.175 & .652 & & \\
\hline & 5 & I don’t avoid extra duties and responsibilities. & .756 & -.409 & .281 & .643 & & \\
\hline & 6 & I always work particularly hard. & 694 & .121 & -.805 & .576 & & \\
\hline & 7 & $\begin{array}{l}\text { I seek out training and other ways of improving my } \\
\text { performance at work. }\end{array}$ & .766 & .048 & -.527 & .572 & & \\
\hline \multirow{5}{*}{$\begin{array}{l}\text { Psychological } \\
\text { health }\end{array}$} & 1 & Feeling unhappy and depressed & .583 & -.131 & -.132 & .255 & \multirow[t]{5}{*}{.752} & .754 \\
\hline & 2 & Capable making decision & .749 & -.717 & .706 & .365 & & \\
\hline & 3 & Face up problems & .678 & .008 & -.258 & .317 & & \\
\hline & 4 & Able to concentrate & .770 & -.592 & .261 & .394 & & \\
\hline & 5 & Enjoy normal activities & .772 & -.119 & .307 & .276 & & \\
\hline \multirow[t]{4}{*}{$\begin{array}{l}\text { Moral } \\
\text { Disengagement }\end{array}$} & 1 & $\begin{array}{l}\text { It is okay to sacrifice animals to } \\
\text { defend human. }\end{array}$ & .746 & -.222 & -.705 & 1.740 & \multirow[t]{4}{*}{.773} & .788 \\
\hline & 2 & $\begin{array}{l}\text { Neglecting animal welfare is okay as } \\
\text { long as animals' lives have been saved. }\end{array}$ & .497 & -.394 & .148 & 1.487 & & \\
\hline & 3 & $\begin{array}{l}\text { Considering the goal of our organization, } \\
\text { it's hardly a sin to degrade animal } \\
\text { welfare a bit. }\end{array}$ & .651 & -.434 & -.291 & 1.692 & & \\
\hline & 4 & $\begin{array}{l}\text { People shouldn't be held accountable for } \\
\text { treating animals wrongly when they } \\
\text { were just doing what an authority } \\
\text { figure told them to do. }\end{array}$ & .889 & .058 & -.209 & 1.384 & & \\
\hline
\end{tabular}


Table 5 (continued)

\begin{tabular}{|c|c|c|c|c|c|c|c|c|}
\hline Factor & Number & Item & $\begin{array}{l}\text { Factor } \\
\text { load }\end{array}$ & Skewness & Kurtosis & $\begin{array}{l}\text { Harman's } \\
\text { one factor } \\
\text { test } \\
\text { Explained } \\
\quad \text { varia- } \\
\quad \text { tion }\end{array}$ & KMO & $\alpha$ \\
\hline & 5 & $\begin{array}{l}\text { People can't be blamed for treating animals } \\
\text { that are technically wrong when all their } \\
\text { colleagues are doing it too. }\end{array}$ & .862 & .306 & .086 & 1.343 & & \\
\hline & 6 & $\begin{array}{l}\text { It's no big deal that a small flaw occurs when I take } \\
\text { care of animals. }\end{array}$ & .610 & -.390 & .034 & 1.297 & & \\
\hline & 7 & $\begin{array}{l}\text { Some animals have to be treated roughly because } \\
\text { they lack feelings that can be hurt. }\end{array}$ & .612 & .108 & -.617 & 1.235 & & \\
\hline & 8 & $\begin{array}{l}\text { Animals get mistreated have usually done something } \\
\text { to bring it on themselves. }\end{array}$ & .661 & -.086 & -.603 & 1.107 & & \\
\hline \multirow[t]{7}{*}{ Mindfulness } & 1 & $\begin{array}{l}\text { I was more concerned with being open to my } \\
\text { experiences than controlling or changing them. }\end{array}$ & 694 & .009 & -.291 & 1.036 & \multirow[t]{7}{*}{.906} & .927 \\
\hline & 2 & $\begin{array}{l}\text { I was curious about what I might learn about myself } \\
\text { by taking notice of how I react to certain thoughts, } \\
\text { feelings or sensations. }\end{array}$ & .701 & -.079 & -.216 & .999 & & \\
\hline & 3 & $\begin{array}{l}\text { I was curious to see what my mind was up to from } \\
\text { moment to moment. }\end{array}$ & .730 & .039 & -.127 & .957 & & \\
\hline & 4 & $\begin{array}{l}\text { I was curious about each of the thoughts and feelings } \\
\text { that I was having. }\end{array}$ & .756 & -.059 & -.337 & .903 & & \\
\hline & 5 & $\begin{array}{l}\text { I remained curious about the nature of each } \\
\text { experience as it arose. }\end{array}$ & .766 & -.096 & -.197 & .842 & & \\
\hline & 6 & I was curious about my reactions to things. & .724 & -.032 & -.048 & .837 & & \\
\hline & 7 & $\begin{array}{l}\text { I was curious about what I might learn about myself } \\
\text { by just taking notice of what my attention gets } \\
\text { drawn to. }\end{array}$ & .717 & -.228 & -.041 & .791 & & \\
\hline
\end{tabular}

Source: Data compiled in this study

\section{References}

Abendroth, M., \& Flannery, J. (2006). Predicting the risk of compassion fatigue: A study of hospice nurses. Journal of Hospice \& Palliative Nursing, 8(6), 346-356.

Adams, R. E., Boscarino, J. A., \& Figley, C. R. (2006). Compassion fatigue and psychological distress among social workers: A validation study. American Journal of Orthopsychiatry, 76(1), 103-108.

Alexandra, V. (2019). The role of social worldviews and self-control in moral disengagement. Personality and Individual Differences, 143, 74-79.

Bandura, A. (1986). Social foundations of thought and action. Englewood Cliffs, NJ: Prentice-Hall.

Bandura, A. (1990). Selective activation and disengagement of moral control. The Journal of Social Issues, 46(1), 27-46.

Bandura, A., Adams, N. E., \& Beyer, J. (1977). Cognitive processes mediating behavioral change. Journal of Personality and Social Psychology, 35(3), 125-139.

BBC (2017 February 2) The vet who 'euthanised' herself in Taiwan.

Beattie, M. M., Konttinen, H. M., \& Volanen, S. (2020). Social cognitions and mental health as predictors of adolescents' mindfulness practice. Mindfulness, 11(21 February), 1204-1217.

Berger, R., \& Gelkopf, M. (2011). An intervention for reducing secondary traumatization and improving professional self-efficacy in well baby clinic nurses following war and terror: A random control group trial. International Journal of Nursing Studies, 48(5), 601-610.
Bolduc, R., Bigras, N., Godbout, N., Hébert, M., \& Daspe, M. È. (2018). Childhood cumulative trauma and depressive symptoms in adulthood: The role of mindfulness and dissociation. Mindfulness, 9(5), 1594-1603.

Bride, B. E., Radey, M., \& Figley, C. R. (2007). Measuring compassion fatigue. Clinical Social Work Journal, 35(3), 155-163.

Brotto, L. A., Seal, B. N., \& Rellini, A. (2012). Pilot study of a brief cognitive behavioural versus mindfulness-based intervention for women with sexual distress and a history of childhood sexual abuse. Journal of Sex \& Marital Therapy, 38(1), 1-27.

Burtson, P. L., \& Stichler, J. F. (2010). Nursing work environment and nurse caring: Relationship among motivational factors. Journal of Advanced Nursing, 66(8), 1819-1831.

Caprara, G. V., Alessandri, G., Tisak, M. S., Paciello, M., Caprara, M. G., Gerbino, M., \& Fontaine, R. G. (2012). Individual differences in personality conducive to engagement in aggression and violence. European Journal of Personality, 27(3), 290-303.

Chaskalson, M. (2011). The mindful workplace: Developing resilient individuals and resonant organizations with MBSR. Oxford, United Kingdom: Wiley.

Cocker, F., \& Joss, N. (2016). Compassion fatigue among healthcare, emergency and community service workers: A systematic review. International Journal of Environmental Research and Public Health, 13(6), 618.

Coetzee, S. K., \& Klopper, H. C. (2010). Compassion fatigue within nursing practice: A concept analysis. Nursing \& Health Sciences, 12(2), 235-243. 
Corcoran, K. J. (1983). Emotional separation and empathy. Journal of Clinical Psychology, 39(5), 667-671.

Daigneault, I., Dion, J., Hébert, M., \& Bourgeois, C. (2016). Mindfulness as mediator and moderator of post-traumatic symptomatology in adolescence following childhood sexual abuse or assault. Mindfulness, 7(6), 1306-1315.

Dickinson, G. E., Roof, P. D., \& Roof, K. W. (2010). End-of-life issues in United States veterinary medicine schools. Society \& Animals, $18(2), 152-162$.

Doolittle, B. R. (2010). The impact of behaviors upon burnout among parish-based clergy. Journal of Religion and Health, 49(1), 88-95.

Earley, M. D., Chesney, M. A., Frye, J., Greene, P. A., Berman, B., \& Kimbrough, E. (2014). Mindfulness intervention for child abuse survivors: A 2.5-year follow-up. Journal of Clinical Psychology, $70(10), 933-941$.

Fida, R., Paciello, M., Tramontano, C., Fontaine, R. G., Barbaranelli, C., $\&$ Farnese, M. L. (2015). An integrative approach to understanding counterproductive work behavior: The roles of stressors, negative emotions, and moral disengagement. Journal of Business Ethics, 130(1), 131-144.

Figley, C. R. (2002a). Compassion fatigue: Psychotherapists' chronic lack of self-care. Journal of Clinical Psychology, 58(11), 14331441.

Figley, C. R. (2002b). Treating compassion fatigue. New York: Brunnerroutledge.

Figley, C. R. \& Roop, R. G. (2006). Compassion fatigue in the animal care community, humane society. Washington, D. C.: The humane society of the United States.

Fiske, S. (2004). Social beings: A Core motives approach to social psychology. New York: Wiley.

Flin, R., \& Maran, N. (2004). Identifying and training non-technical skills for teams in acute medicine. Quality and Safety in Health Care, 13, $80-84$.

Francis, L. J., P. Hills, \& Kaldor, P. (2009). The Oswald clergy burnout scale: Reliability, factor structure and preliminary application among Australian clergy. Pastoral Psychology, 57(5-6), 243-252.

Goldberg, D. (1972). The detection of psychiatric illness by questionnaire: A technique for the identification and assessment of nonpsychotic psychiatric illness. London, New York: Oxford University Press.

Harris, C. L. (2002). The emotional labour of barristers: An exploration of emotional labour by staus professionals. Journal of Management Studies, 39(4), 553-584.

Hooper, C., Craig, J., Janvrin, D. R., Wetsel, M. A., \& Reimels, E. (2010). Compassion satisfaction, burnout, and compassion fatigue among emergency nurses compared with nurses in other selected inpatient specialties. Journal of Emergency Nursing, 36(5), 420-427.

Hsu, J.-M., Tsai, P.-Y., Huang, S.-B., Hsieh, Y.-C., Cheng, S.-F., \& Shih, S.-M. (2016). A training course for cultivating self-compassion to hospice care professionals. Taiwan Journal of Hospice Palliative Care, 21(3), 316-328.

Hudson, K. G., Lawton, R., \& Hugh-Jones, S. (2020). Factors affecting the implementation of a whole school mindfulness program: A qualitative study using the consolidated framework for implementation research. BMC Health Services Research, 20(133), 1-13.

Hyland, P., Lee, R. A., \& Mills, M. (2015). Mindfulness at work: A new approach to improving individual and organizational performance. Industrial and Organizational Psychology, 8(4), 576-602.

Jacobsona, J. M., Rothschilda, A., Mirza, F., \& Shapiroz, M. (2013). Risk for burnout and compassion fatigue and potential for compassion satisfaction among clergy: Implications for social work and religious organizations. Journal of Social Service Research, 39(4), 455-468.

Joinson, C. (1992). Coping with compassion fatigue. Nursing, 22(1), 116-121.
Josefsson, T., Larsman, P., Broberg, A. G., \& Lundh, L. G. (2011). Selfreported mindfulness mediates the relation between meditation experience and psychological well-being. Mindfulness, 2(1), 49-58.

Kabat-Zinn, J. (1994). Wherever you go, there you are: Mindfulness meditation in everyday life. New York: Hyperion Press.

Kabat-Zinn, J. (2016). Defining mindfulness-mindful. Retrieved November 14, 2017, from http://www.mindful.org/jon-kabat-zinndefining-mindfulness/.

Kahler, S. C. (2015). Moral stress the top trigger in veterinarians' compassion fatigue: Veterinary social worker suggests redefining veterinarians' ethical responsibility. Journal of the American Veterinary Medical Association, 246(1), 16-18.

Keidel, G. C. (2002). Burnout and compassion fatigue among hospice caregivers. American Journal of Hospice and Palliative Medicine, 19(3), 200-205.

Kline, R. B. (2005). Principles and practice of structural equation modeling ( $\left.2^{\text {nd }} E d.\right)$. New York: Guilford.

Lally, R. M. (2005). Oncology nurses share their experiences with bereavement and self-care. Oncology Nursing Society, 20(10), 4-5.

Lau, M. A., Bishop, S. R., Segal, Z. V., Buis, T., Anderson, N. D., Carlson, L., Shapiro, S., Carmody, J., Abbey, S., \& Devins, G. (2006). The Toronto mindfulness scale: Development and validation. Journal of Clinical Psychology, 62(12), 1445-1467.

Leisink, P., \& Steijn, B. (2009). Public service motivation and job performance of public sector employees in the Netherlands. International Review of Administrative Sciences, 75(1), 35-52.

Mahlo, L. \& Windsor, T. D. (2020). Older and more mindful? Age differences in mindfulness components and well-being. Aging \& Mental Health, 02 mar, 1-13.

Mazzone, A., \& Camodeca, M. (2019). Bullying and moral disengagement in early adolescence: Do personality and family functioning matter? Journal of Child and Family Studies, 28, 2120-2130.

McArthur, M. L., Andrews, J. R., Conor, B., \& Susan, J. H. (2017). The prevalence of compassion fatigue among veterinary students in Australia and the associated psychological factors. Article in Journal of Veterinary Medical Education, 44(1), 9-21.

Medland, J., Howard-Ruben, J., \& Whitaker, E. (2004). Fostering psychosocial wellness in oncology nurses: Addressing burnout and social support in the workplace. Oncology Nursing Forum, 31(1), 4754.

Moore, C., Detert, J. R., Treviño, L. K., Baker, V. L., \& Mayer, D. M. (2012). Why employees do bad things: Moral disengagement and unethical organizational behavior. Personnel Psychology, 65(1), 148.

Neff, K. D. (2003a). Self-compassion: An alternative conceptualization of a healthy attitude toward oneself. Self and Identity, 2(2), 85-101.

Neff, K. D. (2003b). The development and validation of a scale to measure self-compassion. Self and Identity, 2(3), 223-250.

Neville, K., \& Cole, D. A. (2013). The relationships among health promotion behaviors, compassion fatigue, burnout, and compassion satisfaction in nurses practicing in a community medical center. Journal of Nursing Administration, 43(6), 348-354.

Nolte, A. G., Downing, C., Temane, A., \& Hastings-Tolsma, M. (2017). Compassion fatigue in nurses: A metasynthesis. Journal of Clinical Nursing, 26(3), 4364-4378.

Omair, A. (2015). Selecting the appropriate study design for your research: Descriptive study designs. Journal of Health Specialties, 3(3), 153-156

Potter, P., Deshields, T., Divanbeigi, J., Berger, J., Cipriano, D., Norris, L., \& Olsen, L. (2010). Compassion fatigue and burnout: Prevalence among oncology nurse. Clinical Journal of Oncology Nursing, 14(5), 56-62.

Probst, T. M., Petitta, L., Barbaranelli, C., \& Austin, C. (2020). Safetyrelated moral disengagement in response to job insecurity: Counterintuitive effects of perceived organizational and supervisor support. Journal of Business Ethics, 162(2), 343-358. 
Randall, K. J. (2004). Burnout as a predictor of leaving Anglican parish ministry. Review of Religious Research, 46(1), 20-26.

Rosenthal, M. Z., Hall, M. L. R., Palm, K. M., Batten, S. V., \& Follette, V. M. (2005). Chronic avoidance helps explain the relationship between severity of childhood sexual abuse and psychological distress in adulthood. Journal of Child Sexual Abuse, 14(4), 25-41.

Thoits, P. A. (1995). Stress, coping, and social support processes: Where are we? What next? Journal of Health and Social Behavior, 35, 5379.

Waldo, D. (1980). The Enterprise of Public Administration. Novato, California, US: Chandler \& Sharp Publishers.

Wang, X., Lei, L., Yang, J., Gao, L., \& Zhao, F. (2017). Moral disengagement as mediator and moderator of the relation between empathy and aggression among Chinese male juvenile delinquents. Child Psychiatry \& Human Development, 48, 316-326.

Yeung, P., Bridey, W., \& Chilvers, B. L. (2017). Exploring wellness of wildlife carers in New Zealand: A descriptive study. Anthrozoös, $30(4), 549-563$

Yoder, E. A. (2010). Compassion fatigue in nurses. Applied Nursing Research, 23(4), 191-197.

Zander, M., Hutton, A., \& King, L. (2010). Coping and resilience factors in pediatric oncology nurses. Journal of Pediatric Oncology Nursing, 27(2), 94-108.

Publisher's Note Springer Nature remains neutral with regard to jurisdictional claims in published maps and institutional affiliations. 